\title{
Introduction to the Special Issue on the Man and the Machine
}

\author{
Thomas Burri and Isabelle Wildhaber*
}

This special issue assembles five articles ensuing from a conference on "The Man and the Machine: When Systems Take Decisions Autonomously", which took place on June 26 and 27, 2015, at the University of St. Gallen in Switzerland.

The aim of the conference was to explore the broader implications of artificial intelligence, machine learning and autonomous robots and vehicles. Alphabet's Deep Mind is just one example about whom we know, at least a little, and who, we are told, will be good. ${ }^{1}$ Autonomous vehicles are also about to enter the market and our phones have begun to verbalize at us. Private drones are being regulated by the US Federal Aviation Administration. ${ }^{2}$ The five papers in this special issue address some of the legal issues the broader development raises. ${ }^{3}$

The first article is on "The Implications of Modern Business-Entity Law for the Regulation of $\mathrm{Au}^{-}$ tonomous Systems" and is written by Shawn Bayern. ${ }^{4}$ It essentially proposes a way for individuals, based on the law as it stands now, to grant legal personality to autonomous systems. The proposal is to encase autonomous systems in a limited liability corporation the aim and objective of which is determined by the system itself. The ties between the members and the corporation are then severed. Consequently, the system becomes fully autonomous within the legal

* Thomas Burri is an Assistant Professor of International and European law, and Isabelle Wildhaber is a Full Professor of Private Law, Business and Labour Law, both at the University of St. Gallen (HSG).

1 Eric Schmidt and Jared Cohen, 'Inventive artificial intelligence will make all of us better', Time, 28 December 2015, p. 20.

2 Cecilia Kang, 'Drone Registration Rules Are Announced by F.A.A.', 14 December 2015 (<http://mobile.nytimes.com/2015/12/ 15/technology/drone-registration-rules-are-announced-by-faa html?smid=fb-nytimes\&smtyp=cur\&_r=0\&referer=http://m facebook.com>, last visit: 13 June 2016).

3 The conference "The Man and the Machine" was interdisciplinary by design. The call for papers that was issued in the fall 2014 was successful in attracting papers from various backgrounds of research from all over the world. However, as organizers, we refrained from pushing the interdisciplinary thrust right through to the publication, for when it comes to publishing authors are often bound to serve their disciplinary audiences. As a substitute we mention these papers which are (about to be) sense. Bayern's proposal is made on the basis of US law, but the idea at the heart of it is of broader interest, namely also from a European perspective. In a similar vein, the EU RoboLaw "Guidelines on Regulating Robotics" from $2014^{5}$ suggest that in limited circumstances robots might be granted a legal status similar to a corporation. This could allow them to perform some transactions, such as entering into contracts.

The second article, "Autonomous Systems as Creative Agents under the EU Framework for Intellectual Property", by Madeleine de Cock Buning, lays out in detail the challenges that arise when systems create works of art autonomously, without a human author having a controlling hand in this process. She draws on a number of legal orders and on the way the law historically dealt with new technologies, such as photography, to show how these challenges are and could be addressed.

The third article, "The Pros and Cons of Legal Automation and Its Governance", by Ugo Pagallo and Massimo Durante, looks at autonomous systems from a more theoretical perspective. It discusses the governance issues that autonomous systems pose as well as the most recent case law.

The fourth articles discusses what comes to the mind of most when they hear of autonomous sys-

published now here: Michael Anderson and Susan Leigh Anderson, "Towards Ensuring Ethical Behaviour from Autonomous Systems: A Case-Supported Principle-Based Paradigm", 42 Industrial Robot: An International Journal 4, pp. 324-331; Kate Darling, "Who's Johnny?' Anthrophomorphic Framing in HumanRobot Interaction, Integration, and Policy", forthcoming in Robot Ethics 2.0, Patrick Lin, George Bekey, Keith Abney, and Ryan Jenkins (eds), MIT Press; Sahlil K. Mehra, "Anti-Trust and the Robo-Seller: Competition in the Time of Algorithms", forthcoming in 100 Minnesota Law Review; James I. Walsh, "Lethal Autonomous Weapons and Responsibility Attribution", published as "Political Accountability and Autonomous Weapons" in 2015

Research and Politics October-December, pp. 1-6. Four more papers were presented which stood at an earlier stage of research.

4 The article is published concomitantly in the Stanford Technology Law Review.

5 Erica Palmerini, Federico Azzarri, Fiorella Battaglia, et al., "Guidelines on Regulating Robotics", 22 September 2014, available on the internet at: http://www.robolaw.eu. 
tems, namely autonomous vehicles. In her article, "Liability Issues Concerning Self-Driving Vehicles", Melinda Florina Lohmann discusses the answers the law has, and might have, when cars drive by themselves and cause damage. She finds that the manufacturer of autonomous vehicles will have to bear more of the liability risks than is currently the case for ordinary vehicles.

The special issue concludes with "The Politics of Robot Autonomy". Thomas Burri deconstructs the notion of robot autonomy. Through the prisms of the Darpa Robotics Challenge, which took place in California in June 2015, and the "Campaign to Stop Killer Robots", which influences the international humanitarian law-making process under way in Geneva, he identifies two "views" of robot autonomy. The article then attempts to explain why these two "views" diverge.

The conference "The Man and the Machine" inspired us to envisage other events broadly on automation, robotics and artificial intelligence. On 7 and 8 July 2016, we further explore the legal personality of robots in a workshop entitled "In the Company of Robots". On October 28 and 29, 2016, we will then organize a conference on "Automation, Robotics and Artificial Intelligence - Perspectives in Swiss Law". It aims at exploring several questions raised in our discussions from a legal perspective. The key to integrating automation, robotics and AI into our lives is to identify the potential legal issues even if the underlying law is uncertain or developing. Once the compliance issue is identified, necessary resources can be directed at finding the best answer.

For now, we wish to conclude by expressing a note of thanks. Our first and foremost thanks go to the Law School of the University of St. Gallen and in particular the profile area "Enterprise - Law, Innovation, and Risk" for the generous funding of the conference. Furthermore, we would like to thank Silvio Hänsenberger, whose tireless work and irreproachable organizational order made the conference a success. We see it as a positive sign that the conference inspired Silvio to embark on a doctoral dissertation on liability issues and autonomous drones. 